\title{
Mild Iron Overload in an African American Man with SLC40A1 D270V
}

\author{
Pauline L. Lee ${ }^{a}$ Terry Gaasterland ${ }^{b}$ James C. Barton ${ }^{c, d}$ \\ ${ }^{a}$ Department of Molecular and Experimental Medicine, Scripps Research Institute, and ${ }^{b}$ Institute for Genomic \\ Medicine and Scripps Institution of Oceanography, University of California San Diego, La Jolla, Calif., and 'Southern \\ Iron Disorders Center, and ${ }^{\mathrm{d}}$ Department of Medicine, University of Alabama at Birmingham, Birmingham, Ala., USA
}

\section{Key Words}

Ferroportin · FLVCR1 P542S • Iron overload

\begin{abstract}
We report on a 46-year-old black man who resided in Alabama with normal transferrin saturation, mild hyperferritinemia, chronic hepatitis $\mathrm{C}$, and 3+ iron in hepatocytes and Kupffer cells. Exome sequencing revealed heterozygosity for SLC40A1 D270V (exon 7, c.809A $\rightarrow$ T), a mutation previously reported only in 1 black patient with iron overload who resided in the Republic of South Africa. The present patient was also heterozygous for: heme transporter FLVCR1 novel allele P542S (exon 10, 1624C $\rightarrow$ T); FLVCR1 T544M (rs3207090); hemopexin (HPX) R371W (rs75307540); ferritin scavenger receptor (SCARA5) R471H (rs61737287); and transferrin receptor (TFRC) G420S (rs41295879). He had no HFE, TFR2, HJV, or HAMP mutations. D270V was not detected in 19 other African Americans with iron overload who resided in Alabama. The allele frequency of SLC40A1 D270V in 258 African American adults who participated in a health appraisal clinic was 0.0019 (95\% confidence interval 0-0.0057). D270V could explain 'classical' ferroportin hemochromatosis phenotypes in some African Americans.

Copyright $\odot 2012$ S. Karger AG, Basel
\end{abstract}

(C) 2012 S. Karger AG, Basel

0001-5792/12/1281-0028\$38.00/0

Fax +4161306 1234

E-Mail karger@karger.ch

www.karger.com
Accessible online at:

www.karger.com/aha

\section{Introduction}

The SLC40A1 gene encodes ferroportin, an iron exporter and the hepcidin receptor [1]. Some SLC40A1 mutations cause an uncommon, heterogeneous group of iron overload disorders characterized by an autosomal dominant pattern of inheritance [2,3]. The SLC40A1 polymorphism Q248H occurs in some Blacks with hyperferritinemia who reside in the US [4-7], but the odds ratio of the association of Q248H with iron overload is not significantly elevated [8]. No other SLC40A1 missense mutations believed to cause elevated iron measures have been previously described in African Americans [2]. Herein, we report the identification of SLC40A1 D270V in a 46-yearold African American man with mild iron overload who resided in Alabama. The relationship of D270V to his iron phenotype is discussed in the context of other mutations we identified by genome sequencing and the associations of other SLC4OA 1 mutations to iron overload phenotypes in persons of sub-Saharan African native descent.

\section{Case Report}

At a routine annual examination, a 46-year-old African American man from south Alabama had hemoglobin $14.5 \mathrm{~g} / \mathrm{dl}$, mean corpuscular volume $82 \mathrm{fl}$, serum aspartate aminotransferase 51 $\mathrm{U} / \mathrm{l}$, serum iron $152 \mu \mathrm{g} / \mathrm{dl}$, transferrin saturation $37 \%$, and serum

Dr. James C. Barton

Southern Iron Overload Disorders Center

Suite 626, 2022 Brookwood Medical Center Drive

Birmingham, AL 35243 (USA)

Tel. +1 205877 2888, E-Mail ironmd@isp.com 
ferritin $353 \mathrm{ng} / \mathrm{ml}$. He was diagnosed to have hepatitis $\mathrm{C}$ at age 17 years and had positive serum hepatitis $\mathrm{C}$ antibody tests with mild intermittent elevation of serum aminotransferase levels on several occasions during the ensuing 29 years. We observed that he had hepatitis $\mathrm{C}$, genotype 1 . He had no symptoms or abnormal physical findings. He had a history of mild hypertension. He consumed a normal diet, did not drink alcohol, and never took iron supplements or donated blood. He had no family history of blood, iron, or liver abnormalities. His father had died of unknown cause. His mother was alive but was not available for study. His brother had died as a child in an accident.

Further testing revealed serum iron $187 \mu \mathrm{g} / \mathrm{dl}$, transferrin saturation $41 \%$, and serum ferritin $559 \mathrm{ng} / \mathrm{ml}$. Percutaneous liver biopsy was interpreted as mononuclear infiltration and grade 2 fibrosis in the portal triads, no hepatocellular necrosis, 3+ stainable iron in hepatocytes and Kupffer cells [9], and minimal fatty change. He declined to undergo phlebotomy therapy or other treatment for iron overload or hepatitis. At age 57 years, he reported no symptoms and had a normal physical examination, and his serum levels of aminotransferases were normal. He declined to undergo repeat serum iron measurements.

\section{Methods}

Genetic Testing of the Present Patient

HFE mutation analysis to identify C282Y, H63D, and S65C alleles was performed as previously described [4]. Direct sequencing of SLC4OA1 was performed as previously described [4]. Further mutation analysis was performed by exome sequencing with Roche Nimblegen SeqCap EZ Human Exome Library version 2 according to the manufacturer's instructions. Next-generation sequencing was performed with an Illumina GAIIx. We obtained $51,236,724$ pairs of reads of length 100 , for a total of 10.25 billion bases of raw data. The SLC40A1 D270V mutation (chromosome 2: 190428903) was found through computational analysis of genome-wide coding region sequences with $52 \times$ coverage and validated by Sanger sequencing [10]. Mapping, single nucleotide polymorphism (SNP) calling, and SNP annotation of exome sequencing reads were performed using Bowtie (bowtie-bio.sourceforge.net), SAMtools (samtools.sourceforge.net) and SeattleSeq (gvs.gs.washington.edu/SeattleSeqAnnotation), respectively. Details of exome sequencing are available upon request and will be described elsewhere.

Evaluation of Other African Americans for SLC40A1 D270V

We performed direct sequencing of SLC40A1 in 19 other unrelated African American adults from Alabama who had primary iron overload phenotypes. We also estimated the allele frequency of SLC40A1 D270V in African Americans by testing DNA specimens obtained with informed consent from the Kaiser/The Scripps Research Institute Genetics Bank from a convenience sample of 258 African American adult participants in a health appraisal clinic [11]. Genotyping was performed by real-time PCR using the Biorad CFX thermal cycler and Precision Melt software (Biorad, Hercules, Calif., USA). Amplification was performed using SLC40A1 primers FPN ex7F (AGTACTACTAATAATTGGCTTTT) and FPN ex7Rn (GACCCATCCATCTCGGAAGGT), and Sso Eva green Taq polymerase, with 1 cycle of $95^{\circ} \mathrm{C}$ at $3-\mathrm{min}$

African American Iron Overload and SLC40A1 D270V initial denaturation, and 39 cycles of $95^{\circ} \mathrm{C}$ for $20 \mathrm{~s}, 57^{\circ} \mathrm{C}$ for $5 \mathrm{~s}$, and $72^{\circ} \mathrm{C}$ for $5 \mathrm{~s}$. The melt curve analysis was performed between 70 and $95^{\circ} \mathrm{C}$ at 0.1 degree increments. All ambiguous and nonwild-type genotype calls were validated by direct Sanger sequencing (Genewiz, San Diego, Calif., USA).

\section{Results}

\section{Genetic Testing of the Present Patient}

HFE mutation analysis did not detect HFE C282Y, H63D, or S65C alleles. Exome sequencing revealed heterozygosity for a mutation in SLC40A1 (D270V; exon 7, c.809A $\rightarrow$ T) identified as novel by SeattleSeq but which was described previously by Zaahl et al. [12] in 1 of 22 South African black patients with iron overload. The SLC40A1 Q248H polymorphism was not detected in the present patient. He was homozygous for BMP2 R190S, where serine is the common allele. We identified mutations in other genes related to iron homeostasis (table 1). In particular, we found heterozygosity for: a novel allele in the heme transporter gene FLVCR1 (P542S; exon 10, c.1624C $\rightarrow$ T); FLVCR1 T544M (rs3207090); hemopexin (HPX) R371W (rs75307540); ferritin scavenger receptor gene (SCARA5) R471H (rs61737287); and transferrin receptor (TFRC) G420S (rs41295879). Exome sequencing did not detect any mutations in the hemochromatosis genes $H F E$, transferrin receptor-2 (TFR2), hemojuvelin $(H J V)$, or hepcidin (HAMP).

\section{Evaluation of Other African Americans for SLC40A1 D270V}

None of the 19 other adult black patients with iron overload phenotypes had SLC40A1 D270V. Exome sequencing of 4 of these 19 other patients confirmed that they did not have SLC40A1 D270V. Overall, we observed D270V in 1 of 20 unrelated African Americans with iron overload phenotypes [allele frequency approx. 0.025 (1/40)]. The allele frequency of SLC40A1 D270V mutation in 258 African American adults who participated in a health appraisal clinic was 0.0019 (1/516 alleles). Clinical observations on the one adult positive for D270V were not available.

\section{Discussion}

We excluded FLVCR1 P542S as a candidate mutation for iron overload in the present case because the proline residue at amino acid position 542 is instead a serine at 
Table 1. Selected mutations identified by exome sequencing in an African American man with mild iron overload

\begin{tabular}{|c|c|c|c|c|c|c|c|c|c|c|c|c|}
\hline Gene ID & $\begin{array}{l}\text { Chromosome } \\
\text { position }\end{array}$ & $\begin{array}{l}\text { Ref- } \\
\text { base }\end{array}$ & $\begin{array}{l}\text { Geno- } \\
\text { type }\end{array}$ & $\begin{array}{l}\text { Known/ } \\
\text { novel }\end{array}$ & rsID & $\begin{array}{l}\text { Amino acid } \\
\text { change }\end{array}$ & $\begin{array}{l}\text { cDNA } \\
\text { Position }\end{array}$ & PolyPhen & Afrofq & Eurofq & SNPQual & ReadCnt \\
\hline$A C V R 1 B$ & 12_52380898 & G & $\mathrm{A} / \mathrm{G}$ & known & 34050429 & NA & NA: 1433 & U/benign & 17 & 0 & 231 & 196 \\
\hline CD163 & $12 \_7637769$ & G & $\mathrm{A} / \mathrm{G}$ & known & 61729512 & T901M & 2702 & benign & NA & NA & 210 & 31 \\
\hline FLVCR1 & 1_213068588 & $\mathrm{C}$ & $\mathrm{C} / \mathrm{T}$ & novel & NA & P542S & 1624 & $\mathbf{U}$ & NA & NA & 161 & 185 \\
\hline GLRX3 & 10_131959150 & $\mathrm{C}$ & $\mathrm{C} / \mathrm{T}$ & known & 2274217 & P123S & 367 & benign & 8 & 28 & 160 & 90 \\
\hline HNF4G & $8 \_76468282$ & G & $\mathrm{A} / \mathrm{G}$ & known & 1805098 & M227I & 681 & benign & 1.8 & 42 & 228 & 96 \\
\hline$H P X$ & 11__6452889 & G & $\mathrm{A} / \mathrm{G}$ & known & 75307540 & R371W & 1111 & $\mathrm{U}$ & NA & NA & 32 & 7 \\
\hline IL6 & 7_22767137 & $\mathrm{C}$ & $\mathrm{T} / \mathrm{T}$ & known & 2069830 & P32S & 94 & benign & 8 & 0 & 49 & 4 \\
\hline NFKB1 & 4_103528817 & $\mathrm{T}$ & $\mathrm{G} / \mathrm{T}$ & known & 4648099 & H712Q & 2136 & $\begin{array}{l}\text { benign/possibly } \\
\text { damaging }\end{array}$ & 6 & 0 & 76 & 18 \\
\hline STAT5A & 17__40461436 & $\mathrm{C}$ & $\mathrm{C} / \mathrm{T}$ & novel & NA & T719M & 2156 & $\mathrm{U}$ & NA & NA & 32 & 4 \\
\hline TFRC & 3_-195791240 & $\mathrm{C}$ & $\mathrm{C} / \mathrm{T}$ & known & 41295879 & G420S & 1258 & benign & NA & NA & 169 & 86 \\
\hline
\end{tabular}

Exome sequencing identified several genes related to iron homeostasis with known or novel mutations annotated by SeattleSeq. PolyPhen predictions, from lowest to highest degree of potential consequence, are 'benign', 'unknown' (U), 'possibly damaging', and 'probably damaging'. Minor allele frequencies are given for African (Afrofq) and European (Eurofq) populations when known and NA is given when unknown. The minor allele is not always the same as the reference base (Refbase), as in BMP2, where the Refbase is the minor allele and the mutation identified by SeattleSeq is the major allele. SNPQual = SNP Single nucleotide polymorphism quality score; ReadCnt = read count; $\mathrm{NA}=$ not available. the homologous position in rhesus monkey, dog, and opossum. FLVCR1 T544M is a polymorphism that occurs at a high allele frequency in the general population. $B M P 2$ was eliminated as a candidate gene for the iron overload phenotype of the present patient because he was homozygous for the common allele that encodes serine at amino acid position 190 . Thus, SLC40A1 was the only gene in which we identified a mutation by exome sequencing that is known to be associated with an iron overload phenotype when present in a heterozygous configuration.

We report the occurrence of SLC40A1 D270V heterozygosity in a black man with a mild iron overload phenotype who resided in Alabama. He was the only one of 20 unrelated black Americans tested with primary iron overload phenotypes from Alabama who had D270V (mean allele frequency $0.025 ; 95 \% \mathrm{CI} 0-0.076$ ). In the initial description of SLC40A1 D270V by Zaahl and colleagues [12], only 1 of 22 black iron overload patients who resided in the Republic of South Africa was heterozygous for SLC40A1 D270V (mean allele frequency 0.023; 95\% CI $0-0.069$ ) [12]. D270V was not detected in 20 South African black control subjects [12]. The allele frequency of
SLC40A1 D270V mutation in 258 African American adults from a health appraisal clinic sample was 0.0019 (95\% CI 0-0.0057). On 9 January 2011, SLC40A1 D270V had not been reported in the GenBank SNP database.

The aspartic acid at position 270 of ferroportin (or orthologous locus) is conserved in most species except in frog in which there is a threonine and a glycine instead of an aspartic acid residue, and in zebrafish, in which there is a methionine residue [13]. SIFT (sorting intolerant from tolerant) predicts the $\mathrm{D} 270 \mathrm{~V}$ mutation to be 'tolerated' and PolyPhen (polymorphism phenotyping) predicts the consequence of the mutation to be 'unknown' [this study and 3]. We propose that the previous identification of D270V in a South African black patient with iron overload [12] and in the present African American with a mild iron overload phenotype indicates that $\mathrm{D} 270 \mathrm{~V}$ is probably a pathogenic mutation and not a benign sequence variant, and that this allele may occur predominantly in Blacks of sub-Saharan African descent.

SLC40A1 D270V affects the third intracellular domain of ferroportin [1]. SLC40A1 G267D (exon 7; c. $1104 \mathrm{G} \rightarrow \mathrm{A}$ ), adjacent to $\mathrm{D} 270 \mathrm{~V}$, alters the same domain 
and was associated with hyperferritinemia transmitted as an autosomal dominant trait in 5 members of a family of Chinese descent [14]. In that report, there was no mention of liver biopsy or phlebotomy therapy in family members who had hyperferritinemia and SLC40A1 G267D. Thus, it is not possible to exclude SLC40A1 G267D as a mutation that causes iron overload or, if so, in which hepatic cell excess iron is deposited. In contrast, SLC40A1 L233P (exon 7; c.698T $\rightarrow$ C) affects a more proximal aspect of the third intracellular domain $[1,15]$. To date, only 1 subject has been reported to have SLC40A1 L233P: an Italian patient with a 'non-classical' ferroportin hemochromatosis phenotype and severe iron overload [15].

SLC40A1 Q248H (rs11568350), although not detected in the present case, occurs as a polymorphism in South African Blacks (allele frequency approximately 0.09) and in African Americans (allele frequency approx. 0.05) [8]. This frequency estimate of the Q248H polymorphism is consistent with the one we reported previously in African Americans [controls 0.08 (16/200); serum ferritin $>350$ $\mathrm{ng} / \mathrm{ml}$ in females, $>500 \mathrm{ng} / \mathrm{ml}$ in males, 0.17 (12/92)] [4]. Q248H is sometimes associated with hyperferritinemia, especially in men and in Q248H homozygotes [4-6]. Regardless, Q248H is not associated with a significantly increased odds ratio for iron overload in African or African American subjects [8] and the allele frequency of Q248H was not higher in African Americans with high serum iron measures than in control subjects [6]. An African American man with ALAS2 R452S and SLC40A1 R561G had severe multi-organ iron overload, although ALAS2
R452S was the predominant cause of his iron overload $[16,17]$. SLC40A1 G339D, L384M, and L384B are also common in African Americans, but have no defined association with abnormal iron phenotypes [4].

In persons with 'classical' ferroportin hemochromatosis, serum iron measures and complications of iron overload typical of 'non-classical' ferroportin and other types of hemochromatosis are relatively uncommon [3]. Observations in the present patient are consistent with 'classical' ferroportin hemochromatosis, including age of presentation, normal transferrin saturation, mild hyperferritinemia, relatively low mean corpuscular volume, and mild iron deposition in hepatocytes and Kupffer cells. Iron overload and liver phenotypes similar to those of the present patient are also relatively common in African Americans with iron overload $[4,9,18,19]$. Alteration of the iron phenotype in the present patient, either by mutations in genes other than SLC4OA1 that we identified or by hepatitis $\mathrm{C}$, cannot be excluded. Taken together, we conclude that SLC40A1 D270V is an uncommon allele that could explain iron overload and liver phenotypes consistent with 'classical' ferroportin hemochromatosis in some African Americans.

\section{Acknowledgments}

This is TSRI manuscript number MEM 21552. This work was supported by NIH R01 DK53505-12, U54 RR025204, The Beutler Foundation, NIH 1RC2EY020678-01, and the Southern Iron Disorders Center.

\section{References}

1 Lee PL, Beutler E: Regulation of hepcidin and iron-overload disease. Annu Rev Pathol 2009;4:489-515.

2 Barton JC, Edwards CQ, Phatak PD, Britton RS, Bacon BR: Hemochromatosis Associated with Ferroportin Gene (SLC40A1) Mutations. Handbook of Iron Overload Disorders. Cambridge, Cambridge University Press, 2010, pp 171-180.

-3 Mayr R, Janecke AR, Schranz M, Griffiths WJ, Vogel W, Pietrangelo A, Zoller H: Ferroportin disease: a systematic meta-analysis of clinical and molecular findings. J Hepatol 2010;53:941-949.

-4 Beutler E, Barton JC, Felitti VJ, Gelbart T, West C, Lee PL, Waalen J, Vulpe C: Ferroportin 1 (SCL40A1) variant associated with iron overload in African-Americans. Blood Cells Mol Dis 2003;31:305-309.
5 Gordeuk VR, Caleffi A, Corradini E, Ferrara F, Jones RA, Castro O, Onyekwere O, Kittles R, Pignatti E, Montosi G, Garuti C, Gangaidzo IT, Gomo ZA, Moyo VM, Rouault TA, MacPhail P, Pietrangelo A: Iron overload in Africans and African-Americans and a common mutation in the SCL4OA1 (ferroportin 1) gene. Blood Cells Mol Dis 2003;31:299304.

-6 Barton JC, Lafreniere SA, Leiendecker-Foster C, Li H, Acton RT, Press RD, Eckfeldt JH: HFE, SLC40A1, HAMP, HJV, TFR2, and FTL mutations detected by denaturing high-performance liquid chromatography after iron phenotyping and HFE $\mathrm{C} 282 \mathrm{Y}$ and $\mathrm{H} 63 \mathrm{D}$ genotyping in 785 HEIRS Study participants. Am J Hematol 2009;84:710-714.
7 Rivers CA, Barton JC, Gordeuk VR, Acton RT, Speechley MR, Snively BM, LeiendeckerFoster C, Press RD, Adams PC, McLaren GD, Dawkins FW, McLaren CE, Reboussin DM: Association of ferroportin Q248H polymorphism with elevated levels of serum ferritin in African Americans in the Hemochromatosis and Iron Overload Screening (HEIRS) Study. Blood Cells Mol Dis 2007;38: 247-252.

8 Barton JC, Acton RT, Lee PL, West C: SLC40A1 Q248H allele frequencies and Q248H-associated risk of non-HFE iron overload in persons of sub-Saharan African descent. Blood Cells Mol Dis 2007;39:206211.

9 Barton JC, Acton RT, Richardson AK, Brissie RM: Stainable hepatic iron in 341 African American adults at coroner/medical examiner autopsy. BMC Clin Pathol 2005;5:2. 
10 Lee PL, Gelbart T, West C, Halloran C, Felitti V, Beutler E: A study of genes that may modulate the expression of hereditary hemochromatosis: transferrin receptor-1, ferroportin, ceruloplasmin, ferritin light and heavy chains, iron regulatory proteins (IRP)1 and -2 , and hepcidin. Blood Cells Mol Dis 2001;27:783-802.

11 Beutler E, Felitti V, Gelbart T, Ho N: The effect of HFE genotypes on measurements of iron overload in patients attending a health appraisal clinic. Ann Intern Med 2000;133: 329-337.

12 Zaahl MG, Merryweather-Clarke AT, Kotze MJ, van der MS, Warnich L, Robson KJ: Analysis of genes implicated in iron regulation in individuals presenting with primary iron overload. Hum Genet 2004;115:409417.
13 UCSC Genome Browser. http://genome. ucsc.edu.2012.

14 Cremonesi L, Forni GL, Soriani N, Lamagna M, Fermo I, Daraio F, Galli A, Pietra D, Malcovati L, Ferrari M, Camaschella C, Cazzola $\mathrm{M}$ : Genetic and clinical heterogeneity of ferroportin disease. Br J Haematol 2005;131: 663-670.

15 Girelli D, De D, I, Bozzini C, Campostrini N, Busti F, Castagna A, Soriani N, Cremonesi L, Ferrari M, Colombari R, McVey WD, Kaplan J, Corrocher R: Clinical, pathological, and molecular correlates in ferroportin disease: a study of two novel mutations. J Hepatol 2008; 49:664-671.
6 Sussman NL, Lee PL, Dries AM, Schwartz MR, Barton JC: Multi-organ iron overload in an African-American man with ALAS2 R452S and SLC40A1 R561G. Acta Haematol 2008;120:168-173.

17 Lee PL, Reid TJ, III, Bottomley SS, Barton JC: Sideroblastic anemia, iron overload, and ALAS2 R452S in African-American males: phenotype and genotype features of five unrelated patients. Am J Hematol 2011;86:787789.

18 Barton JC, Edwards CQ, Bertoli LF, Shroyer TW, Hudson SL: Iron overload in African Americans. Am J Med 1995;99:616-623.

19 Wurapa RK, Gordeuk VR, Brittenham GM Khiyami A, Schechter GP, Edwards CQ: Primary iron overload in African Americans. Am J Med 1996;101:9-18. 